\title{
Study on the Differences Effect between Accounting Audit and Quality Audit \\ Xiaohong Lu
}

Shandong University of Finance and Economics, Jinan, Shandong, 250014

Keywords: Accounting Audit, Quality Audit, Difference Effect

\begin{abstract}
Accounting audit is already a mature discipline, which has more experience and rules, but the quality of the audit is the development of quality management to the recent product, not much experience and rules. The content of accounting audit is economic activity, no human factor, and quality management includes people, machine, material, law, ring content, therefore, quality audit has a large number of human factors, its objectivity is not as good as accounting audit.
\end{abstract}

\section{Introduction}

Auditing is an independent economic monitoring activity. A country has a variety of economic oversight activities, involving a number of economic management. In our country, the financial sector to fulfill the financial supervision responsibilities to ensure the distribution of financial funds and the use of compliance; tax department to fulfill the duties of tax supervision to ensure that taxpayers timely tax, integrity. However, there are inherent weaknesses in finance, taxation and other economic supervision. It is difficult to monitor the problem of irregularities in foreign countries. It is also characterized by its unity and its own business. The audit supervision is a specialized work, itself without economic management responsibilities, with a strong independence and comprehensive, to the financial, tax and other departments of the activities of a comprehensive, in-depth review and evaluation.

\section{Concept and Characteristics of Audit Sampling}

Internal auditors in the audit business implementation process, from the audit and evaluation of the overall audit to take a certain number of representative samples for testing, the results of the sample review to infer the overall characteristics, and make an audit conclusion of an audit method "is China The internal auditing standard 2108 defines the concept of audit sampling from the point of view of statistical sampling, which emphasizes the sample representation and the quantitative analysis of the audit results. Statational sampling and non-statistical sampling are two kinds of methods of audit sampling. Statistical sampling is based on Statistical principle and probability theory, follow the random, determine the necessary sample size, analyze the sample audit results of the representative, if necessary, the implementation of alternative or additional audit procedures. Non-statistical sampling is based on internal audit experience and subjective willingness to select samples and the sample audit results do not do quantitative analysis, only the sample of the problem found in the qualitative analysis and evaluation, if necessary, the implementation of retrospective or extended audit.

The general characteristics of the sample inferred from the relative number and the average number of indicators. The total unit signs can not be expressed in terms of the number of relative indicators to illustrate the overall number of units with a certain mark in the proportion of the total, commonly used in the control of the effectiveness of the test analysis, apply to the property sampling; Unit signs can be expressed in terms of numbers, with the average index to illustrate the overall unit of the discrete units, commonly used in account and transaction balance analysis, applicable to variable sampling. In practice, attention should be paid to the probability scale sampling (PPS sampling) of statistical sampling, which uses the attribute sampling principle to draw the conclusion expressed by the amount. The sample estimation method of the overall method is somewhat estimated and the interval estimation method. Point estimation is to directly use the 
sample average index or relative number of indicators to infer the overall indicators, such as: mean estimate, the difference between the estimated and the ratio of estimates. Interval valuation method is to use the sample average index or relative number of indicators to add and subtract errors, infer the overall indicators of the region.

\section{Analysis of the Differences of Evidence}

Refers to the auditors in the implementation of an audit business process, in order to form an audit opinion and obtain the various credentials. Each audit result can be seen as a carrier of audit evidence, which contains the auditors to form the audit findings and audit recommendations and collected a variety of information. The forensic work includes the collection, identification and comprehensive audit evidence, which is the core of the audit work. In a certain sense, the whole audit work are a purposeful, systematic collection of audit evidence, identification of audit evidence and make judgments of the process. Auditing evidence is important for the entire audit. First, the audit opinion and conclusions must be based on audit evidence. The auditor must use sufficient convincing evidence to substantiate the facts and nature of the matter under review and submit an audit opinion accordingly to arrive at the audit conclusion. In this way, the audit conclusion can be trusted. Second, the audit evidence is also an important tool to control the quality of audit work. The audit project manager must regularly review the audit evidence collected by the auditors and prepare the audit working papers in order to judge the quality of the audit staff, supervise the auditors to comply with the requirements of the independent audit standards, and continuously improve operational capacity and efficiency.

Related to the audit criteria and capable of formal records are factual statements or other information. It can be qualitative or quantitative. Obtained has means of a document, by way of presentation (interview) or on-site observation. Analysis: Due to the specificity of management, quality audit are generally only available in the internal evidence, because the internal evidence of the test force is relatively small, in the quality audit must be carefully analyzed to exclude the adverse effects of adverse information and reduce its role, so that Quality audit is more effective. Oral evidence, due to quality management, including the management of people, should try to adhere to the use of descriptive oral evidence, and insist on the use of large sample method, that is, the number of people to talk, to a wide range. In addition, there is no other way. Analytical review of evidence is a special method of analyzing data in accounting audits and refers to an analysis by an auditor of an important ratio or trend of the audited entity, including investigating unusual changes in these ratios or trends, as well as their associated amounts and correlations Differences in information. The main purpose of the analytical review is to reveal anomalous changes and differences, and to provide clues to further auditing, at least to the attention of the auditors. As an economical and effective method of auditing, analytical review is increasingly valued by national auditors. In the quality audit has a reference, you can examine the quality of the unit by the observation and analysis, to provide guidance for further work.

\section{Differences in the Plan}

The development of an audit plan can clearly define the intended purpose of the audit and the general measures and strategies adopted to achieve this goal, so that the CPA has a good idea and a pre-planning role for the entire audit. Arrange appropriate work progress, staffing and coordination, can maintain a reasonable audit costs, and is conducive to cooperation with the unit under review, so as to improve the efficiency of the audit work. The implementation of the audit plan, certified public accountants can be targeted to collect adequate and appropriate audit evidence. Through the inspection of the implementation of the audit plan, the audit team can complete the work of the effective supervision, assessment and evaluation.

Is a description of an audit activity and arrangement that is required to be documented. The quality audit presents a separate audit program to include planning, organizing and implementing the necessary activities. Analysis: Accounting audit plan in the assessment of risk has a very 
important and prominent role, which is consistent with the accounting audit responsibility requirements, accounting and accounting legal responsibility and risk is always there, so the audit plan highlights the risk assessment The It is important to assess the risk before implementing the audit. In theory, different risks can be used to minimize risks when different risks are taken after a risk assessment. The planning work around the nature of the sample, the sample size, the sampling organization, and the sampling quality of work are called sample design. The main factors that should be taken into account in the design of the sample are: audit objectives, overall auditing and sampling units, sampling and non-sampling risks, trustworthiness, tolerable deviations, expected overall deviations and stratification. In the sampling method because there is not much involved in the quality of the audit, this article not much discussion, ask the reader to read the relevant theoretical papers. Quality audits are also risky, but can not be compared with accounting audits. Therefore, in practice, you can use some of the initial. For example, first estimate the quality management status of the audited entity based on experience, and then estimate how much of the sample is reviewed to determine the sampling plan and sample size.

\section{Target Differences Analysis}

The auditors must have an in-depth understanding of the management's determination of the financial statements as they identify the starting point and the end result of the specific audit objectives and the development of the audit process. The basic duty of the auditors is to determine whether the management of the audited entity has reason and basis for the determination of its accounting statements. Therefore, the specific audit objectives should be for specific account balances or transaction categories, in order to confirm the management of the financial statements of each identified to collect and evaluate audit evidence. Auditing the specific objective (objective audit objective) is the audit of the overall goal of the specific steps, need to be based on the overall audit objectives and the jurisdiction of the management of the unit to determine the financial statements to determine. Obtain audit evidence to prove that the management of the audited entity to its accounting statements, the auditors must be for each identified to develop specific audit objectives. Once sufficient evidence has been obtained to achieve the specific objectives of the audit, the auditor has reason to confirm that the accreditation of the audited entity is reasonable. Table 3 gives the specific objectives of each identified, namely, inability, completeness, accuracy, classification, closure, detailed matching, realizable value, rights and obligations, expression and disclosure of nine. It is worth noting that there is not a one-to-one relationship between the identification of the management and the specific audit objectives, but rather more detailed.

The purpose of the quality audit is to determine what should be done in the audit, including: determining the compliance of the auditor's management system or part thereof with the audit criteria; assessing the ability of the management system to meet legal requirements and contractual requirements; and assessing the effectiveness of the management system in achieving specific objectives; identify the potential improvement aspects of the management system. These purposes are closely related to the auditee and have nothing to do with other aspects.

The integrity requirements are largely ignored in the quality audit, which is consistent with the quality management requirements. Quality management requires the identification process, but does not require that all processes that have occurred are documented in detail. In order to avoid serious rules in economic management, Trample, clearly require all the transactions have occurred in the process must be detailed records. As a result, we can introduce some of the integrity requirements in the quality audit, such as the ability to require some processes to record integrity at different times. Expression and disclosure in the accounting audit is related to the requirements in the quality audit requirements are more vague, different auditors to express and disclose the same example will be a big difference. Organizations can clearly identify and disclose standards and requirements for quality audits based on their own characteristics. 


\section{Conclusion}

The accounting audit plan has a very important and prominent role in the assessment of risk, which is consistent with the responsibility of accounting audit. The legal responsibility and risk of accounting audit are always present, so the risk assessment is highlighted in the audit plan. It is important to assess the risk before implementing the audit. In theory, different risks can be used to minimize risks when different risks are taken after a risk assessment. The planning work around the nature of the sample, the sample size, the sampling organization, and the sampling quality of work are called sample design. The main factors that should be taken into account in the design of the sample are: audit objectives, overall auditing and sampling units, sampling and non-sampling risks, trustworthiness, tolerable deviations, expected overall deviations and stratification.

\section{References}

[1] Ge Jiapu, Chen Shoude. Discussion on Quality Evaluation of Financial Report [J]. Accounting Research, 2001 (11)

[2] Huang Shizhong. Challenges and Thinking of Accounting Information Quality of Listed Companies [J]. Journal of Accounting Research, 2001 (10)

[3] Wei Minghai, Liu Feng, Shi Kunxiang. Accounting transparency [J]. Accounting Research, 2001 (09)

[4] $\mathrm{Xu}$ Hairong. Comparison and Enlightenment of Supervisor Auditing between Chinese and Foreign Companies [J]. Journal of Audit and Economy Research, 2001 (02)

[5] Zhao Baoqing. Discussion on Quality Control of Enterprise Internal Audit [J] .Journal of Auditing and Economic Research, 2001 (01) 